\section{AB0495 INCREASED WORK LOSS DURING PREGNANCY IN WOMEN WITH SYSTEMIC LUPUS ERYTHEMATOSUS COMPARED TO MATCHED HEALTHY CONTROLS}

Birgit Blomjous ${ }^{1}$, Marieke Ter Wee ${ }^{2}$, Alexandre Voskuyl ${ }^{1}$, Hanneke de Vries ${ }^{3}$, Irene E.M. Bultink ${ }^{1}{ }^{1}$ Amsterdam UMC, Vrije Universiteit Amsterdam, Amsterdam Rheumatology and immunology Center, Amsterdam, Netherlands; ${ }^{2}$ Amsterdam UMC, Vrije Universiteit Amsterdam, Amsterdam Rheumatology and immunology Center and Epidemiology and Biostatics, Amsterdam, Netherlands; ${ }^{3}$ Amsterdam UMC, Vrije Universiteit Amsterdam, Obstetrics and Gynecology, Amsterdam, Netherlands

Background: Women with systemic lupus erythematosus (SLE) might be more vulnerable to reduce or stop working during pregnancy because of the increased risk of pregnancy complications compared to the general population. However, no data on work loss during pregnancy and return to work after maternity leave in patients with SLE are available.

Objectives: We aimed to investigate several work outcomes during and after pregnancy in women with SLE compared to matched pregnant controls.

Methods: A case-control study on employment was performed in pregnant women with SLE and matched controls. Matching criteria were age, year of delivery, and number of living infants. Employment was defined as having $\geq 8$ hours/week of paid work before conception. Four work outcomes were investigated: interruption of work for $>1$ week during pregnancy, complete cessation of work for $>1$ week until delivery, reduction in working hours during pregnancy, and the time in weeks to return to work after maternity leave.

Results: A total of 42 women were included (21 SLE patients, 21 controls). Mean SELENA-SLEDAI before pregnancy in SLE patients was 2.6 (SD 2.3). Interruption of work for $>1$ week or completely stop working during pregnancy occurred in 10 SLE women, compared to 2 controls $(\mathrm{OR}=8.6,95 \% \mathrm{Cl}$ [1.6-46.8], $\mathrm{p}=0.012)$. From the women who completely stopped working until delivery $(n=8), 7$ women had SLE (OR=1.4, 95\% $\mathrm{Cl}$ [0.07-28.1], $\mathrm{p}=0.826)$. In addition, in women continuing work, reduction of working hours occurred in 5 women with SLE versus 3 controls (OR=1.9, 95\% Cl [0.4-9.1], $\mathrm{p}=0.436$ ).

After delivery, the median (IQR) duration of return to work after maternity leave was 4 weeks after maternity leave $(0-6.8)$ for women with SLE and 2 weeks later $(0-4)$ for controls (Mann-Whitney $U$ test; $p=0.977$ ). No difference in number of women with delay of return to work after maternity leave (yes/no) was found between women with SLE and controls ( $n=9$ versus $n=11$, respectively; OR=1.0, 95\% Cl [0.3-3.7], $p=0.973$ ). Conclusion: Pregnant women with SLE more frequently completely stop working or reduce working hours compared to matched healthy controls. These findings warrant improved counseling of these women and attention of health care providers, including company doctors.

Disclosure of Interests: Birgit Blomjous Speakers bureau: UCB Pharma BV, Marieke ter Wee Grant/research support from: Nonrestricted grant from Lilly Netherlands BV, Speakers bureau: ARC Preceptorship program, Alexandre Voskuyl: None declared, Hanneke de Vries Grant/research support from: Pfizer, Speakers bureau: UCB Pharma BV, Irene E.M. Bultink Consultant for: Consultant fee from Sanofi Genzyme, Speakers bureau: Speaker fees from Lilly Netherlands BV, MSD Corp, Amgen BV, UCB Pharma BV, Roche Netherlands BV and Sanofi Genzyme DOI: 10.1136/annrheumdis-2019-eular.2981

\section{AB0496 18F-FDG-PET/CT, 11C-METHIONINE-PET/CT AND MULTI- PARAMETRIC MRI IN THE EVALUATION OF DISEASE ACTIVITY AND GLAND FUNCTION IN PRIMARY SJÖGREN'S SYNDROME}

Michele Bombardieri ${ }^{1}$, Coziana Ciurtin ${ }^{2}$, Michalis Kostapanos ${ }^{3,4}$, Elisa Astorri ${ }^{1}$, Anwar Tappuni ${ }^{1}$, Natasha Jordan ${ }^{3}$, Saleem Azeem ${ }^{5}$, Teresa Fuller ${ }^{6}$, Kathleen Port ${ }^{6}$, Nirav Ratia ${ }^{6}$, Andre van Maurik ${ }^{6}$, Calum Gray ${ }^{7}$, Lucy Kershaw ${ }^{7}$, Rob Janiczek ${ }^{6}$, Graham Searle ${ }^{5}$, Paul Galette ${ }^{6}$, Marius de Groot ${ }^{6}$, Neel Patel ${ }^{6}$, Nicolas Wisniacki ${ }^{6}$, Mats Bergstrom ${ }^{6}$, Pilar Jimenez-Royo ${ }^{6}$, Ruth Tarzi ${ }^{6} .{ }^{1}$ Queen Mary University of London, London, United Kingdom; ${ }^{2}$ University College London, London, United Kingdom; ${ }^{3}$ Addenbrooke's Hospital, Cambridge, United Kingdom; ${ }^{4}$ GSK, Cambridge, United Kingdom; ${ }^{5}$ Invicro, London, United Kingdom; ${ }^{6}$ GSK, Stevenage, United Kingdom; ${ }^{7}$ University of Edinburgh, Edinburgh, United Kingdom

Background: Saliva and tear flow rates and minor salivary gland biopsy are typically used to assess gland function and disease activity in primary Sjögren's syndrome (pSS); however, these have limitations. Imaging methods can directly visualize and generate quantitative values in individual glands. ${ }^{18} \mathrm{~F}$-FDG-PET/CT $\left({ }^{18} \mathrm{~F}\right.$-FDG) measures glucose metabolism, a potential surrogate for inflammation; ${ }^{11} \mathrm{C}$-methionine-PET/CT $\left({ }^{11} \mathrm{C}\right.$-met) is an amino acid PET tracer that assesses protein synthesis, a potential surrogate for gland synthetic function.
Objectives: Explore the potential of molecular imaging and multi-parametric MRI to characterize and quantify pSS disease manifestations.

Methods: In this pilot imaging study (203818), patients with pSS diagnosed per AECG criteria, with a EULAR Sjögren's syndrome disease activity index score $\geq 5$, and basal salivary flow $>0.0 \mathrm{~mL} / \mathrm{min}$ or stimulated salivary flow rate $\geq 0.05 \mathrm{~mL} / \mathrm{min}$, underwent ${ }^{18} \mathrm{~F}$-FDG and ${ }^{11} \mathrm{C}-$ met and dynamic contrast-enhanced and diffusion-weighted MRI, followed by minor salivary gland biopsy for histological analysis. Age- and sexmatched healthy volunteers (HV) underwent MRI and ${ }^{11} \mathrm{C}$-met. HV-pSS mean differences (m-diff; 95\% confidence intervals [CI]) were calculated and Pearson's correlation coefficients $(r)$ estimated. Peak PET standard uptake values (SUVpeak) were used in the correlations and SUVmax values were recorded. All methods were compared with routine clinical and laboratory tests.

Results: 12 patients had MRI, ${ }^{18} \mathrm{~F}-\mathrm{FDG}$ and ${ }^{11} \mathrm{C}$-met; while HV $(\mathrm{n}=12)$ had MRI $(\mathrm{n}=12)$ and ${ }^{11} \mathrm{C}$-met $(\mathrm{n}=8)$. A lower ${ }^{11} \mathrm{C}$-met SUVpeak was seen in the parotid (m-diff: $1.4 \mathrm{~g} / \mathrm{mL}[0.4,2.3])$ and submandibular $(\mathrm{m}$ diff: $2.0 \mathrm{~g} / \mathrm{mL}[0.9,3.2])$ glands in pSS versus $\mathrm{HV}$, as was a trend for lower lacrimal gland uptake (m-diff: $0.5 \mathrm{~g} / \mathrm{mL}[-0.2,1.3]$ ) in patients with pSS. On structural MRI, the fat fraction (mean\%) was higher in pSS vs HV in the submandibular glands (m-diff: $-14.8[\mathrm{Cl}:-29.3,-0.4]$ ), with similar trends observed in the parotid glands $(-11.2[-24.3,1.9])$. There was a negative correlation between ${ }^{11} \mathrm{C}$-met uptake and fat fraction $(r:-0.7$ [$0.9,-0.4])$ in the combined parotid glands. There was positive correlation between ${ }^{11} \mathrm{C}$-met uptake and stimulated salivary flow ( $\mathrm{r}: 0.5[0.03,0.8]$ ) and negative correlation for stimulated salivary flow and fat fraction ( $r$ : $0.5(-0.8,-0.1)]$ in the parotid glands; similar correlations were also seen in the submandibular glands. There was negative correlation between the global lymphoid aggregation score on minor salivary gland biopsy and the combined salivary gland fat fraction ( $\mathrm{r}:-0.7[-0.9,-0.2])$. Parotid gland SUVmax ${ }^{18} \mathrm{~F}$-FDG uptake was higher than historical control values (mean: $1.9 \mathrm{~g} / \mathrm{ml}$, [SD: 0.5$]^{1}$ ) in some patients (pSS mean SUVmax: $2.8 \mathrm{~g} / \mathrm{mL}$ [SD: 0.8 , range 1.7-4.6]), with positive correlation between ${ }^{18} \mathrm{~F}-\mathrm{FDG}$ and ${ }^{11} \mathrm{C}$-met uptake ( $\mathrm{r}: 0.7[0.2,0.9]$ ) in the combined salivary glands.

Conclusion: Imaging showed clear differences between pSS and HV and correlated with clinical endpoints. Low ${ }^{11} \mathrm{C}$-met uptake and high fat fraction on MRI may indicate poor residual gland function, while high ${ }^{18} \mathrm{~F}$ FDG and stable ${ }^{11} \mathrm{C}$-met uptake may define a subpopulation that responds well to anti-inflammatory therapies.

\section{REFERENCES}

[1] Basu S, et al. Nucl Med Commun 2008; 29:367-73.

Acknowledgement: Study/editorial support by Fishawack Indicia Ltd, UK funded by GSK.

Disclosure of Interests: Michele Bombardieri Grant/research support from: Celgene, Consultant for: Medimmune, Coziana Ciurtin: None declared, Michalis Kostapanos Consultant for: Is an NHS consultant seconded to the GSK Clinical Cambridge Unit (50\%) and has nothing to disclose., Elisa Astorri: None declared, Anwar Tappuni: None declared, Natasha Jordan: None declared, Saleem Azeem Shareholder of: GSK, Teresa Fuller Shareholder of: GSK, Employee of: GSK, Kathleen Port Shareholder of: GSK, Employee of: GSK, Nirav Ratia Shareholder of: GSK, Employee of: GSK, Andre van Maurik Shareholder of: GSK, Employee of: GSK, Calum Gray: None declared, Lucy Kershaw: None declared, Rob Janiczek Shareholder of: GSK, Employee of: GSK, Graham Searle: None declared, Paul Galette Shareholder of: GSK, Employee of: GSK, Marius de Groot Shareholder of: GSK, Employee of: GSK, Neel Patel Shareholder of: GSK, Employee of: GSK, Nicolas Wisniacki Shareholder of GSK, Employee of: GSK, Mats Bergstrom Shareholder of: GSK, Consultant for: acted as external consultant to GSK, Employee of: GSK, Pilar Jimenez-Royo Shareholder of: GSK, Employee of: GSK, Ruth Tarzi Shareholder of: GSK, Employee of: GSK DOI: 10.1136/annrheumdis-2019-eular.7050

\section{AB0497 SERUM CALPROTECTIN IN SYSTEMIC LUPUS ERYTHEMATOSUS: IS IT A GOOD ACTIVITY BIOMARKER?}

Jordi Camins-Fàbregas, Melania Martínez-Morillo, Aina Teniente-Serra, Annika Nack, Ivette Casafont-Solé, Laia Gifre, Maria Aparicio-Espinar, Anne Riveros, Águeda Prior-Español, Anahy Brandy-Garcia, Clara SangüesaGomez, Susana Holgado, Lourdes Mateo, Eva Martinez-Cáceres, Alejandro Olive. Hospital Universitari Germans Trias i Pujol, Badalona, Spain

Background: Clinical manifestations of systemic lupus erythematosus (SLE) and infections sometimes are difficult to distinguish. In clinical practice low complement and anti(ds)DNA levels are used to assess lupus activity but 